\section{S0SIAfLL- Lä̈̈HETIETEELLINEW AIHAHAUSLEHTI}

Journal of Social Medicine

Päätoimittaja

Sari Räisänen

editor@socialmedicine.fi

Toimitussihteeri

Suvi Määttä

Puh. 0405937048

toimitussihteeri@ socialmedicine.fi

Toimitusneuvosto

Anssi Auvinen, Heikki Hiilamo, Ilmo Keskimäki, Leena Koivusilta, Simo Kokko, Pekka Louhiala, Esa Läärä, Sami Pirkola, Ossi Rahkonen, Arja Rimpelä, Eva Roos ja Päivi Topo

Julkaisija

Sosiaalilääketieteen yhdistys ry

Socialmedicinska föreningen rf

Puheenjohtaja

Peija Haaramo

Terveyden ja hyvinvoinnin laitos

PL 30

0027 I Helsinki

\author{
Sihteeri \\ Sanni Helander \\ Suomen Syöpärekisteri \\ Unioninkatu 20-22 \\ 00120 Helsinki \\ sihteeri@socialmedicine.fi \\ Neljä numeroa vuodessa \\ Tilaushinnat vuonna 2018: \\ Jäsenet $45 €$, opiskelijat $20 €$ \\ (Sosiaalilääketieteen yhdistyksen jäsenmaksu) \\ Muut, yhteisöt ja tilaukset ulkomaille 50€, \\ irtonumerot $13 €+$ postituskulut
}

Tämä julkaisu on saanut TSV:n kautta tieteellisen julkaisutoiminnan avustusta, jota opetus- ja kulttuuriministeriö myöntää Veikkauksen tuotoista

ISSN 0355-5097

Kirjapaino Hermes 0y 2018

\title{
Eutanasia on koko yhteiskunnan asia
}

Kysymys eutanasiasta on yhteiskunnassamme tällä hetkellä ajankohtaisempi kuin koskaan. Eutanasian laillistamiseen tähtäävä kansalaisaloite luovutettiin eduskunnalle helmikuussa 2017, jonka jälkeen asiaa käsiteltiin Sosiaali- ja terveysvaliokunnassa, joka julkaisi sitä koskevan mietinnön 6.4.2018. Mietinnön päätösehdotuksen mukaan eduskunnan tulisi hylätä kansalaisaloitteeseen sisältyvän ehdotuksen lainvalmistelutoimenpiteisiin ryhtymisestä eutanasialain säätämiseksi ja eutanasian laillistamiseksi Suomessa (1). Eutanasiaa vastustavien sekä kannattavien tahojen odotukset kohdistuvat nyt eduskuntaan ja sen äänestyksen tulokseen.

Eutanasia on kiistatta eräs ristiriitaisimmista sekä haastavimmista elämän loppuvaiheen eettisistä kysymyksistä. Se on sidoksissa ihmisen syvimpiin arvoihin ja herättää usein voimakkaita tunteita $(2,3)$. Tämä ilmenee myös nyt käytävässä yhteiskunnallisessa keskustelussa, joka näyttäytyy usein polarisoituneena eutanasiaa kannattavien sekä vastustavien tahojen välillä, vailla osapuolten aitoa pyrkimystä eri näkökulmien ymmärtämiseen, hyväksynnästä puhumattakaan. Aiheen haasteellisuudesta kertoo myös se, että usein keskustelu kääntyy eutanasiasta saattohoitoon, kuten kävi myös eduskunnan lähetekeskustelussa sekä sosiaali- ja terveysvaliokunnan ensimmäisessä käsittelyssä. Valiokunnan silloinen puheenjohtaja Tuula Haatainen piti mahdollisena, että eutanasiaa kannattava kansalaisaloite saattaa eutanasian laillistamisen sijaan johtaa saattohoidon paranemiseen Suomessa (4). Nyt julkaistu mietintö tukee osaltaan Haataisen esittämää arviota, sen sisältäessä ehdotuksen valtioneuvoston asettamasta laajamittaisesta asiantuntijatyöryhmästä, joka selvittäisi elämän loppu- 
vaiheen hyvää hoitoa, itsemääräämisoikeutta sekä saattohoitoa ja eutanasiaa koskevia sääntelytarpeita (1).

\section{AKTIIVINEN TEKO TOISEN IHMISEN ELÄMÄN PÄ̈̈TTÄMISEKSI HÄNEN OMASTA PYYNNÖSTÄÄN}

Sanaa eutanasia on käytetty hyvin monissa asiayhteyksissä ja sille on annettu useita eri merkityksiä hoitotoimista luopumisesta tai pitäytymisestä aina ihmisen elämän päättämiseen, ilman tietoa hänen omasta toiveestaan. Tämä on osaltaan vaikeuttanut eutanasiasta käytävää keskustelua ja saattanut johtaa myös väärinkäsityksiin keskusteluun osallistuvien välillä. Eutanasialla tarkoitetaan kuitenkin "aktiivista tekoa toisen ibmisen elämän päättämiseksi hänen omasta pyynnöstään”. Näin määritelty eutanasia on linjassa Euroopan alueella olevissa eutanasialainsäädännöissä käytettyjen määritelmien kanssa $(3,5)$. Toisinaan eutanasian määritelmässä käytetään myös sanaa surmaaminen (6), mikä on rikos ja siten tuomittavaa kaikissa tilanteissa. Näin ollen eutanasiasta käytetty määritelmä saattaa antaa sille jo lähtökohtaisesti kielteisen sävyn ja vaikuttaa siten osaltaan käytävään keskusteluun.

Eutanasiassa olennaista on kuolemaa toivovan henkilön oma pyyntö, joka on tarkoin harkittu eikä ole syntynyt ulkopuolisen painostuksen tai vaikutuksen tuloksena. Samoin eutanasia tekona on aina tarkoituksellinen ja sen tavoitteena on toisen ihmisen elämän päättäminen. Merkityksellistä on myös se, että eutanasian toteuttaa aina joku toinen, kuin kuolemaa toivova henkilö (5). Näin ollen lääkäriavusteinen itsemurha eroaa eutanasiasta siinä, että ihminen ottaa kuolettavan lääkeannoksen itse, eikä kuolema ole kenenkään toisen tuottama, jolloin eutanasialle asetetut ehdot eivät täyty $(3,5)$.

\section{EUTANASIAAN KOHDISTUVAT ASENTEET OVAT MUUTTUNEET MYÖNTEISIMMIKSI}

Eutanasiaan kohdistuvia asenteita on mitattu sekä erilaisin kyselyin (7-10) että tieteellisin tutkimuksin $(2,3,11)$. Vaikka tieteellisten tutkimusten tuloksia ei voida suoraan verrata toisiinsa mm. käytettyjen määritelmien eroavaisuuksien johdosta, voidaan eutanasiaan kohdistuvien asenteiden katsoa yleisellä tasolla muuttuneen myönteisemmiksi niin Suomessa kuin muuallakin Länsi-Euroopassa (12). Vuosituhannen vaihteessa kolmasosa lääkäreistä (34\%), hieman alle puolet sairaanhoitajista sekä puolet kansalaisista (50\%) ilmaisivat yleisellä tasolla hyväksyvänsä eutanasian (2). Viimeaikaisten tutkimustulosten perusteella eutanasiaan suhtautui myönteisesti lähes puolet $(45 \%)$ lääkäreistä sekä enemmistö osallistuneista sairaanhoitajista $(74 \%)$ ja kansalaisista $(85 \%)(3,11)$. Kyselyiden tulokset näyttäytyvät saman suuntaisina tutkimustulosten kanssa. Tulosten valossa näyttää siltä, että mitä vähemmän henkilö on osallisena eutanasiaprosessissa ja siihen liittyvässä päätöksenteossa, sitä myönteisempi on myös hänen asenteensa. Yksittäistä kansalaista eutanasiakysymys ei välttämättä kosketa lainkaan hänen elämänsä aikana mutta sairaanhoitajat voivat olla osallisena eutanasiaprosessissa oman ammattinsa johdosta. Lääkäreiden osallisuus ja vastuu on kaikkein suurin, olemassa olevan eutanasialainsäädännön, Kanadaa lukuun ottamatta, määritellessä sekä päätöksenteon että toimenpiteen toteuttamisen heidän tehtävikseen $(5,13)$. Tämä saattaa osaltaan selittää kuolevia potilaita hoitavien lääkäreiden eutanasia-asenteiden kielteisyyden (7). Mikäli eutanasia sallittaisiin, heidät todennäköisesti nähtäisiin eutanasian toteuttajina ammattitaitonsa sekä kuolevan potilaan hoitoon liittyvän kokemuksensa johdosta.

\section{TERVEYDENHUOLLON HENKILÖSTÖN OIKEUS KIELTÄYTYÄ OSALLISUUDESTA}

Eutanasiaan kohdistuvien asenteiden myönteisyys ei automaattisesti tarkoita henkilön valmiutta osallistua itse eutanasiaprosessiin. Louhialan tutkimuksessa vähemmistö lääkäreistä (22\%) ilmaisi toteuttavansa eutanasiaa, mikäli se olisi laillista (11). Sairaanhoitajien tutkimuksessa enemmistö $(74 \%)$ ilmaisi valmiutensa osallistua eutanasiaprosessiin, mikäli se olisi laillista (14). Huomioitavaa on kuitenkin se, että tutkimuksessa eutanasiaprosessia käsiteltiin hoitotyön, ei itse toteutuksen näkökulmasta. International Association of Hospice and Palliative Care (IAHPC) korosti vuonna 2017 kannanotossaan terveydenhuollon henkilöstön oikeutta kieltäytyä osallisuudesta eutanasiaprosessiin (15). Tämä oikeus on myös huomioitu eduskunnassa nyt käsitteillä olevassa kansalaisaloitteessa (16). Sairaanhoitajat ovat osaltaan painottaneet osallisuuden vapaaehtoisuutta yhtenä eutanasian laillistamisen edellytyksenä sekä korostaneet vastentahtoisen osallisuuden olevan hoitohenkilöstöä traumatisoivaa (3). Tällä hetkellä sairaanhoitajilla ei Suomessa 
ole oikeutta kieltäytyä ammattitehtävistä omaan etiikkaan tai vakaumukseen perustuen. Mikäli eutanasia sallittaisiin, se muodostaisi poikkeuksen kaikkiin muihin ammattitehtäviin nähden, mikä saattaisi johtaa myös muihin terveydenhuollon henkilöstön ammattitehtäviin liittyvien velvoitteiden uudelleentarkasteluun.

\section{AUTONOMIAN KUNNIOITUS PERUSTEENA EUTANASIAN SALLIMISELLE}

Etenkin eutanasian kannattajat korostavat autonomian kunnioitusta perusteena eutanasian sallimiselle ja katsovat että ihmisellä tulisi oikeus päättää omasta kuolemastaan $(3,17)$. Eutanasiaa toivovan henkilön autonomian kunnioittaminen ei kuitenkaan yksinään ole riittävä eutanasian toteutuksen kannalta. Eutanasian toteutuminen edellyttää aina toisia ihmisiä, jotka ovat valmiita arvioimaan esitetyn pyynnön asianmukaisuuden ja laillisuuden, sekä suorittamaan itse toimenpiteen. Tästä johtuen perustetta onkin kritisoitu siitä, että se ei huomioi riittävästi toisten, esimerkiksi juuri terveydenhuollon henkilöstön autonomiaa $(3,18)$. Samoin kritiikkiä on kohdistettu autonomian kunnioittamisen korostettuun asemaan muistuttamalla sen olevan saman arvoinen hyvän edistämisen, pahan välttämisen sekä oikeudenmukaisuuden periaatteiden kanssa (19). Usein huomiotta jää myös se, että maissa joissa eutanasia on mahdollistettu, henkilöllä on oikeus esittää eutanasiapyyntö, mikä ei kuitenkaan vielä takaa sen toteutumista (5).

\section{RISKI KALTEVALLE PINNALLE JOUTUMISESTA, MIKÄLI EUTANASIA SALLITAAN}

Kaltevaa pintaa on käytetty kuvaamaan tilannetta, jossa eutanasian salliminen on johtanut sen laajenemiseen koskemaan myös muita, haavoittuvia tai päätöksentekoon kykenemättömiä ihmisryhmiä tai tapauksia, joita ei voida oikeuttaa alkuperäisen päätöksen tueksi esitetyillä perusteilla $(3,17)$. Usein tässä yhteydessä viitataan muistisairauksista kärsiviin ihmisiin sekä Belgian eutanasialainsäädännön muutokseen vuonna 2014, jonka seurauksena laki laajeni koskemaan kaiken ikäisiä ihmisiä (5). Esimerkkinä nostetaan myös esiin Hollannissa keskustelun kohteena oleva "tired of living"-ihmisryhmä, johon kuuluvien henkilöiden kärsimys on eksistentiaalista vailla kuolemaan johtavaa sairautta, sekä heidän mahdollinen oikeutensa eutanasiaan (20).
Keskustelun laajenemista koskemaan kansalaisaloitteen tarkoittaman ryhmän ulkopuolisia ihmisiä voidaan pitää hyvin todennäköisenä myös Suomessa, jos eutanasian sallimiseen päädytään. Mikäli eutanasia sallitaan kansalaisaloitteen hengen mukaisesti, sen voidaan katsoa asettavan ihmiset eriarvoiseen asemaan esimerkiksi heidän ikänsä tai sairautensa perusteella. Mikäli asiaa tarkastellaan kärsimyksen näkökulmasta, voi esimerkiksi kysyä miten 17-vuotiaan ja 40-vuotiaan ihmisen kärsimys eroavat toisistaan? Myös Belgian sekä Hollannin kokemukset osoittavat keskustelun saavan uusia muotoja sekä kohdistuvan yhä useampiin ihmis- ja potilasryhmiin. Tämänhetkisen julkisen keskustelun lisäksi väitettä tukevat tutkimustulokset, joiden mukaan osa sekä kansalaisista että sairaanhoitajista olivat valmiita hyväksymään eutanasian dementiaa sekä vakavaa kehitysvammaa sairastavien kohdalla, jotka eivät ota enää mitään kontaktia ympäristöönsä (21). Hollannissa dementian perusteella myönnetyt eutanasiatapaukset ovat lisääntyneet kymmenen vuoden aikana, vuonna 2006 raportoitiin 3 tapausta kun vuonna 2016 raportoitujen tapausten määrä oli 141, joista yhden ei katsottu täyttävän lain asettamia kriteereitä. Tämä tapaus on edennyt rikostutkintaan ensimmäistä kertaa Hollannin eutanasialain säätämisen jälkeen (21-23).

Olemassa olevan tiedon perusteella eutanasian väärinkäytön yleistymistä ei voida kuitenkaan yksiselitteisesti todeta. Esimerkiksi Hollannissa on vuosien 2002-2016 aikana raportoitu yhteensä 49287 tapausta, joista eutanasiakomissioiden arvion perusteella 87 ei täyttänyt lain edellyttämiä huolellisuuskriteereitä (23). Toisaalta tiedetään, ettei kaikkia tapauksia välttämättä raportoida eutanasiakomissioille (24). Samoin sekä Belgiasta että Hollannista on raportoitu tapauksista, joissa potilaan elämä on päätetty ilman hänen nimenomaista pyyntöään, joskin näiden tapausten osuus on laskenut eutanasian laillistamisen jälkeen (25).

\section{SAATTOHOITO JA EUTANASIA}

Suomalaisen saattohoidon tila ja siihen liittyvä kehitystarve on tunnistettu sekä yhteiskunnassa, että kansainvälisissä vertailuissa $(17,26,27)$. Kuolevan mahdollisuus saada asiantuntevaa saattohoitoa ei toteudu yhdenvertaisesti tai tarvelähtöisesti sekä alueellisten että paikallisten ero- 
jen johdosta (17). Eutanasiakeskustelussa on nostettu esiin kaksi eri näkökulmaa, joista toinen on huoli eutanasian muodostumisesta saattohoidon korvikkeeksi. Esitetty huoli tulisi ottaa vakavasti. Saattohoidon kehitystyö on käynnistynyt ja sitä tuleekin jatkaa ja taata riittävät resurssit huolimatta eutanasiakysymyksen lopullisesta ratkaisusta. Kuten ETENE kannanotossaan toteaa, oireiden riittämättömästä hoidosta tai sen pelosta johtuva eutanasiatoive on ennemminkin merkki puutteellisista voimavaroista sekä osaamisesta, kuin kuolemaan avustamisen välttämättömyydestä (17). Toisen näkökulman mukaan eutanasian tarve poistuu saattohoidon kehittämisen myötä. On hyvin todennäköistä, että korkealaatuinen, yhdenvertaisesti saatavilla oleva saattohoito vähentää eutanasiaan kohdistuvaa tarvetta, mutta se tuskin poistaa sitä kokonaisuudessaan. Sekä Belgiassa että Hollannissa toteutettavan saattohoidon tila on arvioitu korkealaatuiseksi $(26,27)$, tästä huolimatta molemmissa maissa toteutettujen eutanasioiden määrä on vuosittain kasvanut $(17,22)$.

\section{LÄHTEET}

(1) Sosiaali- ja terveysvaliokunta. Valiokunnan mietintö StVM 4/2018vp - KAA 2/2017 vp. 2018; Available at:

https://www.eduskunta.fi/FI/vaski/Mietinto/ Sivut/StVM_4+2018.aspx. Accessed 4/6, 2018.

(2) Ryynänen O, Myllykangas M, Viren M, Heino H. Attitudes towards euthanasia among physicians, nurses and the general public in Finland. Public Health (Nature) 2002 11;116(6):322.

(3) Anja Terkamo-Moisio. Complexity of attitudes towards death and euthanasia.University of Eastern Finland, Faculty of Health Sciences; 2016.

(4) Savon sanomat. Eutanasia-aloite johtamassa saattohoidon paranemiseen. 2017; Available at: https://www.savonsanomat.fi/kotimaa/ Eutanasia-aloite-johtamassa-saattohoidonparanemiseen/1067347. Accessed 4/5, 2018.

(5) Nys H. A discussion of the legal rules on euthanasia in Belgium briefly compared with the rules in Luxembourg and the Netherlands. In: Jones D, Gastmans C, MacKellar C, editors. Euthanasia and Assisted Suicide: Lessons from Belgium. Cambridge: Cambridge University Press; 2017. https://doi.org/10.1017/9781108182799.002
Eutanasia on kysymys, joka koskee koko yhteiskuntaa, minkä johdosta siitä tulisi edelleen käydä avointa ja vastavuoroista keskustelua. Se on myös kysymys jota voi ja tulisikin lähestyä hyvin monesta eri näkökulmasta. Jokainen näkökulma on hyvin monitahoinen, eikä kysymyksiin ole yhtä oikeaa vastausta, mikä korostaa eutanasian sidosta eettiseen arvoperustaan sekä itse elämän merkitystä. Mikäli eutanasian sallimiseen päädytään, erityistä huomiota tulisi kiinnittää etenkin heikoimmassa asemassa olevien ihmisryhmien oikeuksien turvaamiseen sekä saattohoidon yhdenvertaiseen saatavuuteen. Eduskunnan äänestyksen tuloksen ollessa päinvastainen, tulee huomio kiinnittää erityisesti kuoleviin ihmisiin, joiden kärsimystä ei parhaallakaan saattohoidolla kyetä lievittämään. Millä keinoin tuetaan heidän ihmisarvoaan väistämättömän kuoleman edessä ja vältytään tilanteelta, jossa he kokevat jääneensä yksin kärsimyksensä kanssa?

(6) Mäki K. Tietoa eutanasiasta. 2017; Available at: https://www.laakariliitto.fi/liitto/etiikka/tietoaeutanasiasta/. Accessed 4/8, 2018.

(7) Lääkäriliitto. Lääkäriliiton kysely: Saattohoito kehittynyt viimeisten vuosien aikana. 2017; Available at:

https://www.laakariliitto.fi/uutiset/ajankohtaista/ laakariliiton-kysely-saattohoito-kehittynytviimeisten-vuosien-aikana/. Accessed 4/9, 2018.

(8) Sairaanhoitajaliitto. Kysely: sairaanhoitajat myönteisiä eutanasialle. 2017; Available at: https://sairaanhoitajat.fi/2017/kyselysairaanhoitajat-myonteisia-eutanasialle/. Accessed 4/9, 2018.

(9) Linkoheimo E. ET:n lukijat kannattavat eutanasiaa. "Vanhuutta on helpompi ajatella, kun tietää, ettei tarvitse kärsiä”. 2017; Available at: https://www.etlehti.fi/artikkeli/terveys/ etn-lukijat-kannattavat-eutanasiaa-vanhuuttahelpompi-ajatella-kun-tietaa-ettei. Accessed 4/8, 2018.

(10) Manninen M. HS-gallup: Eutanasian vastustus vähentynyt entisestään, mutta yhä useampi on epävarma kannastaan. 2017; Available at: https://www.hs.fi/kotimaa/art-2000005476276. html. Accessed 4/8, 2018.

(11) Louhiala P, Enkovaara H, Halila H, Pälve, Vänska J. Finnish physicians' attitudes towards 
active euthanasia have become more positive over the last 10 years. J Med Ethics 2015 04;41(4):353-355.

(12) Cohen J, Van Landeghem P, Carpentier N, Deliens L. Different trends in euthanasia acceptance across Europe. A study of 13 western and 10 central and eastern European countries, 1981-2008. Eur J Public Health 2013 06;23(3):378-380.

(13) The house of commons. BILL C-14. 2016; Available at: http://www.parl. gc.ca/HousePublications/Publication. aspx ? Language $=E \&$ Mode $=1 \&$ DocId $=8309978$. Accessed 3/1, 2018.

(14) Terkamo-Moisio A, Gastmans C, Ryynänen O, Pietilä A. Finnish nurses' attitudes towards their role in the euthanasia process. Nurs Ethics 2017 08/17; 2017/09:0969733017720850.

(15) De Lima L, Woodruff R, Pettus K, Downing J, Buitrago R, Munyoro E, et al. International Association for Hospice and Palliative Care Position Statement: Euthanasia and Physician-Assisted Suicide. J Palliat Med 2017 Jan;20(1):8-14. https://doi.org/10.1089/jpm.2016.0290

(16) Seppänen E, Viinanen I, Soininvaara O, Taipale V. Eutanasia-aloite hyvän kuoleman puolesta. 2016; Available at: https://www.kansalaisaloite.fi/fi/aloite/2212. Accessed 5/24, 2017.

(17) Valtakunnallinen sosiaali- ja terveysalan eettinen neuvottelukunta ETENE. ETENEn kannanotto eutanasiaan. 2017.

(18) Quaghebeur T, Dierckx de Casterlé B, Gastmans C. Nursing and Euthanasia: a Review of Argument-Based Ethics Literature. Nurs Ethics 2009 07;16(4):466-486.

(19) Beauchamp TL, Childress JF. Principles of Biomedical Ethics. 7th ed. New York: Oxford University Press; 2012.

(20) Florijn BW. Extending' euthanasia to those 'tired of living' in the Netherlands could jeopardize a well-functioning practice of physicians' assessment of a patient's request for death. Health Policy 2018 Available online 31 January 2018.
(21) Terkamo-Moisio A, Pietilä A, Lehto JT, Ryynänen O. Attitudes of nurses and the general public towards euthanasia on individuals with dementia and cognitive impairment. Dementia 2017 07/12; 2017/09:1471301217717063.

(22) Regional Euthanasia Review Committees (RTE). Annual Report 2016. 2017.

(23) Miller DG, Dresser R, Kim SYH. Advance euthanasia directives: a controversial case and its ethical implications. J Med Ethics 2018 Mar 3. https://doi.org/10.1136/medethics-2017-104644

(24) Onwuteaka-Philipsen BD, BrinkmanStoppelenburg A, Penning C, de Jong-Krul GJ, van Delden JJ, van der Heide A. Trends in endof-life practices before and after the enactment of the euthanasia law in the Netherlands from 1990 to 2010: a repeated cross-sectional survey. Lancet 2012 Sep 8;380(9845):908-915. https://doi.org/10.1016/S0140-6736(12)61034-4

(25) Emanuel E, Onwuteaka-Philipsen B, Urwin J, Cohen J. Attitudes and practices of euthanasia and physician-assisted suicide in the united states, canada, and europe. JAMA 2016 July 5;316(1):79-90.

https://doi.org/10.1001/jama.2016.8499

(26) Woitha K, Garralda E, Martin-Moreno JM, Clark D, Centeno C. Ranking of Palliative Care Development in the Countries of the European Union. J Pain Symptom Manage 2016 Sep;52(3):370-377. https://doi.org/10.1016/j. jpainsymman.2016.03.008

(27) The Economist Intelligence Unit. The 2015 Quality of Death Index. Ranking palliative care across the world. 2015.

\section{Anja Terkamo-Moisio}

TtT, Sairaanhoitaja, Vapaa tutkija

Itä-Suomen yliopisto

Hoitotieteen laitos 